\title{
Moisture Absorption Characteristics of Natural Fibre Composites
}

\author{
J. Giridhar, Kishore AND R. M. V. G. K. Rło* \\ Department of Metallurgy' \\ Indian Institute of Science \\ Bangalore-560 012, India
}

(Roceived June 9, 1985)

\begin{abstract}
A comparative study was made between the moisture absorption behaviours of sisal and jute fibre composites in an epoxy matrix under immersion conditions. Sisal fibres. in spite of possessing more compact structure than jute fibres, exhibited higher moisture absorption levels in their composite form; contrary to expectations. This tendency was anributed to the high cellulose content and a possible interfacial effect in the rormer.
\end{abstract}

\section{INTRODUCTION}

F the various natural fibres. Jute and sisal Fibres are of INTEREST to researchers of composite materials. These fibres are very abundant in India and often inexpensive as compared to other relatively adranced man-made fibres, like glass. However, the former category are not only inferior in strength, but also suffer from a very high moisture absorption tendency: a property that can be directly attributed to their chemical nature and physical structure.

It is evident from Table 1 that sisal fibres have a higher cellulose content than jute fibres. Sisal fibres find traditional, age-old applications in the form of high strength ropes and floor mats. These materials have not been really examined from a composite angle.

Glass and graphite fibres are noted to be impermeable not only to moisture, but also to the matrix that surrounds them in a composite. These impermeable fibre composites obey the Fickian diffusion process [1-3]. In recent investigations Rao et. al. [4] reported the validity of the Fickian diffusion model for carefully fabricated jute-epoxy composites, the fibres being permeable both to moisture and the matrix resin. They showed that jute fibres absorb as much as $88 \%$ by weight of the matrix resin during the composite preparation. The equilibrium moisture levels in this fibre $(140 \%)$ were reduced to as low as $9.5 \%$

*Materials Science Division, National Aeronautical Laboratory, Bangalore-560 017. India.

Joumal of Reinforced Plastics and Composites, Vol. 5-April $19 S 6$ 
Table 1. Chemical composition of some natural fibres.

\begin{tabular}{cccccc}
\hline & & \multicolumn{3}{c}{ Lignin } \\
$\begin{array}{c}\text { Fibre } \\
\%\end{array}$ & $\begin{array}{c}\text { Cellulose } \\
\%\end{array}$ & $\begin{array}{c}\text { Moisture } \\
\%\end{array}$ & $\begin{array}{c}\text { Ash } \\
\%\end{array}$ & $\begin{array}{c}\text { Pectins } \\
\%\end{array}$ & $\begin{array}{c}\text { Extractives } \\
\%\end{array}$ \\
\hline Jute & 63.24 & 9.93 & 0.68 & 24.41 & 1.42 \\
Sisal & 77.20 & 6.20 & 1.0 & 14.50 & 1.1 \\
\hline
\end{tabular}

in a composite at a fibre volume fraction of 0.70 . These significant findings prompted a similar study of another composite based again on natural fibres.

In this paper, the authors present experimental data on sisal-epoxy composites subjected to water immersion, with a variation in the fibre volume fraction. They compare the absorption trends in sisal and jute fibres before and after resin impregnation and bring out the disparities exhibited by the sisal fibres. They discuss further the drawbacks of sisal fibres in forming good composites and highlight the excellant wettability of jute fibres in a resin matrix.

\section{THEORETICAL ASPECTS}

\section{(a) Diffusion Process}

Diffusion in polymer composites is by and large reported to take place as per the Fickian rule. For a one dimensional diffusion process through either side of a bone dry solid of finite thickness $(h)$, Shen \& Springer [1] give the following expression,

$$
\frac{M_{t}}{M_{m}}=1-\frac{8}{\pi^{2}} \stackrel{\sum}{=} 0_{0}^{\infty} \exp \frac{\left[-(2 j+1)^{2} \pi^{2}\left(D_{x} t / h^{2}\right)\right]}{(2 j+1)^{2}}
$$

As reported by Rao et al, for permeable fibre composites, Equation (1) can be rewritten in a simplified version as

$$
F_{s}=1-\frac{8}{\pi^{2}}\left[\frac{1}{\left.\exp _{\exp }^{\ln \left(D_{c}^{\prime} t / h^{2}\right) \pi^{2}}\right]}\right.
$$

so that an experimental plot of $F_{s}$ versus $D_{c}^{\prime} t / h^{2}$ on an analytical line representing Equation (2) reveals the extent of correlation between the experimental data and the theory. 
The composite diffusion coefficient can be calculated from the moisture absorption plots $\left(M_{t}\right.$ versus $\left.\sqrt{t}\right)$ since

$$
D_{c}^{\prime}=\pi\left(\frac{h}{4 M_{m}}\right)^{2}\left(\frac{M_{2}-M_{1}}{\sqrt{t_{2}}-\sqrt{t_{1}}}\right)^{2}
$$

\section{b. Nature of Natural Fibres}

Considering the physical structure proper, commercial grade jute fibres are made of fine fibrils twisted together to form continuous rovings useful for packing and fastening applications. These fibres have further been proved to have a good potential for large scale use in the composite industry, provided certain precautions are taken. However, lack of sufficient strength on the part of the basic fibrils hinders their being twisted to a high degree of compaction, which imparts to them a loose and open structure in the rovings form. It is interesting to note, however, that the open structure becomes almost impregnaied with the matrix resin during the composite making process, as reported earlier by Rao et al. This is the reason why the moisture absorption level of a virgin jute fibre ( $140 \%$ by weight) is drastically reduced when the jute fibre is impregnated with an epoxy-resin.

Sisal fibres, on the other hand, have a more compact physical structure than jute fibres. It may therefore be expected that virgin jute fibres would exhibit greater resin and moisture absorption levels than sisal fibres. However, upon resin impregnation, these fibres will exhibit moisture absorption properties that very murchrdepend on the level of ręsin absorption into the fibre prior to curing, the celfulose content of the fibre and the resin-fibre interface.

\section{EXPERIMENTAL DETAILS}

Boneredry test specimens $25 \mathrm{~mm} \times 25 \mathrm{~mm} \times 3 \mathrm{~mm}$ were prepared from. unidirectional composite laminates made of commerical grade jute and sisal fibres in a hot curing epoxy matrix (LY 556, HT 972 system supplied by M/s. Ciba Geigy (I) Ltd.). These specimens were then immersed in distilled water maintained at $298^{\circ} \mathrm{K}$. The specimens were periodically withdrawn from the water bath, wiped dry and weighed. The percentage weight increase was calculated as a function of time till the specimens reached equilibrium absorption limits. These measurements were also made on sisal composites of varying fibre volume fractions.

\section{RESULTS AND DISCUSSION}

\section{a. Moisture Absorption Trends}

Figure 1 shows that the sisal fibres absorbed much less resin than the jute fibres prior to curing. Referring to Figure 2 it is seen that, being compact, the sisal fibres absorbed less moisture (about $70 \%$ by weight) than the jute fibres (140\%). Figure 3 shows that the moisture absorption level increases as the 


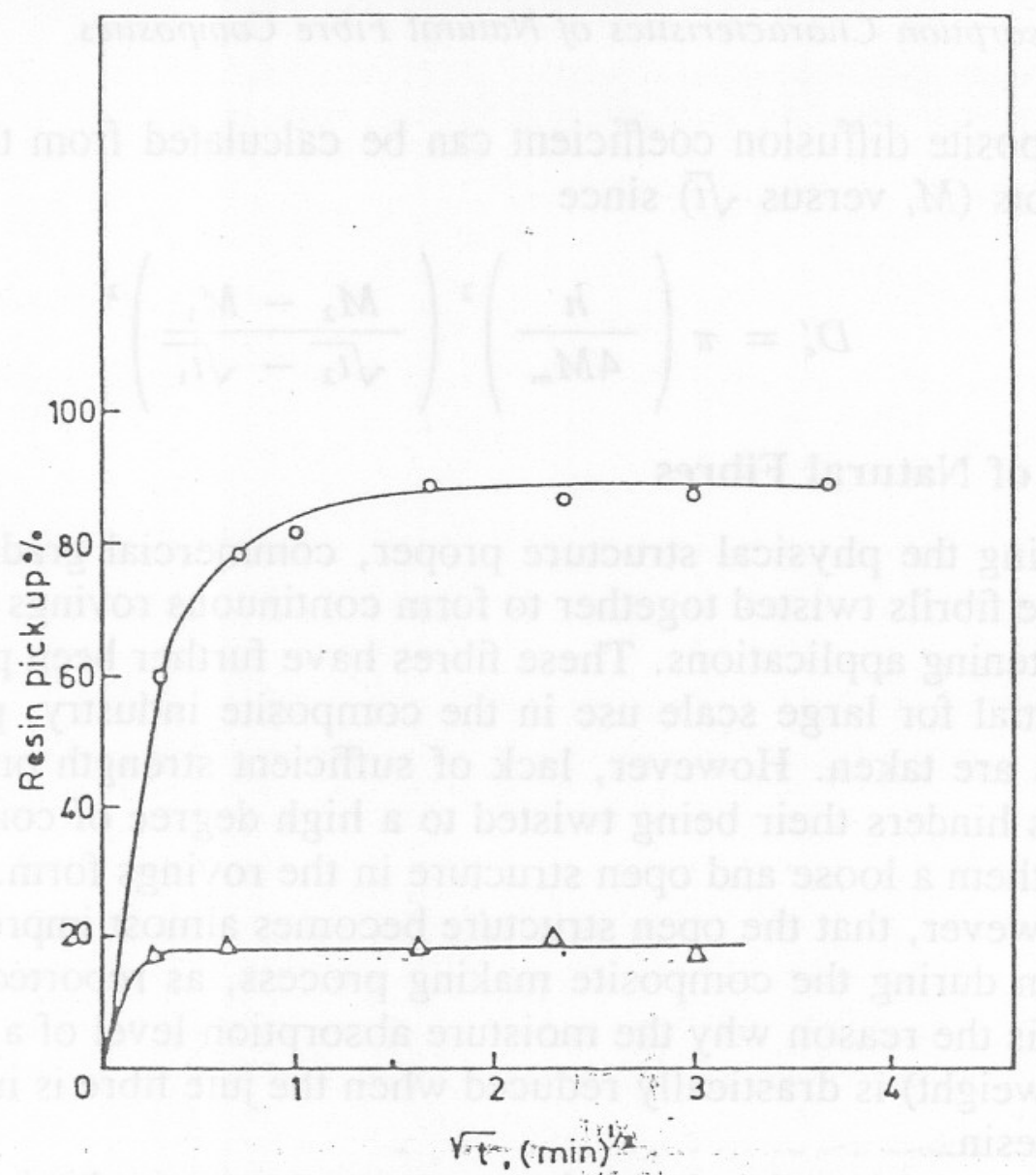

Figure 1. \% resin absorption in sisal $(\Delta)$ and jute $(O)$ fibres.

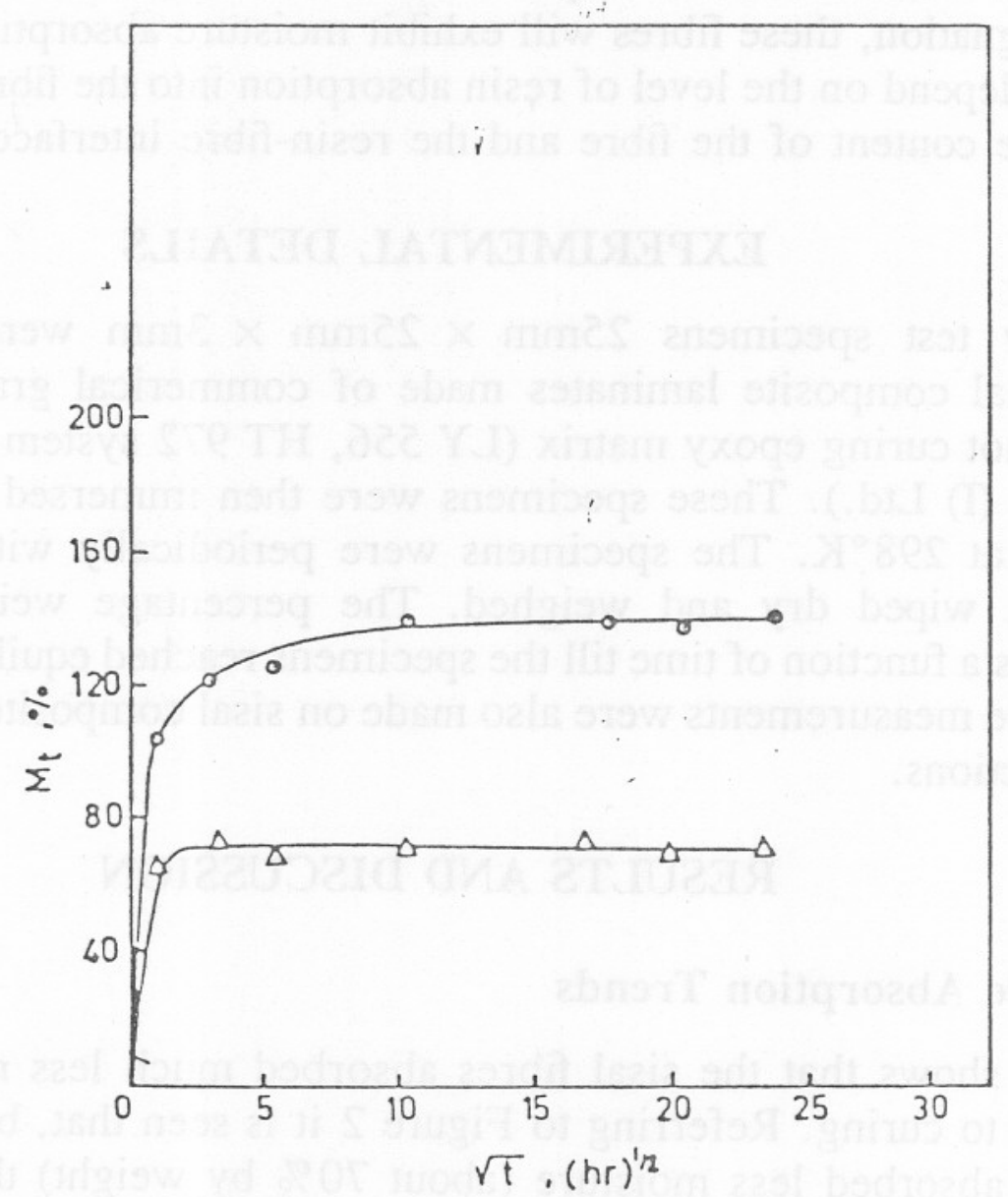

Figure 2. \% moisture absorption in sisal $(\Delta)$ and $(\odot)$ jute fibres. 


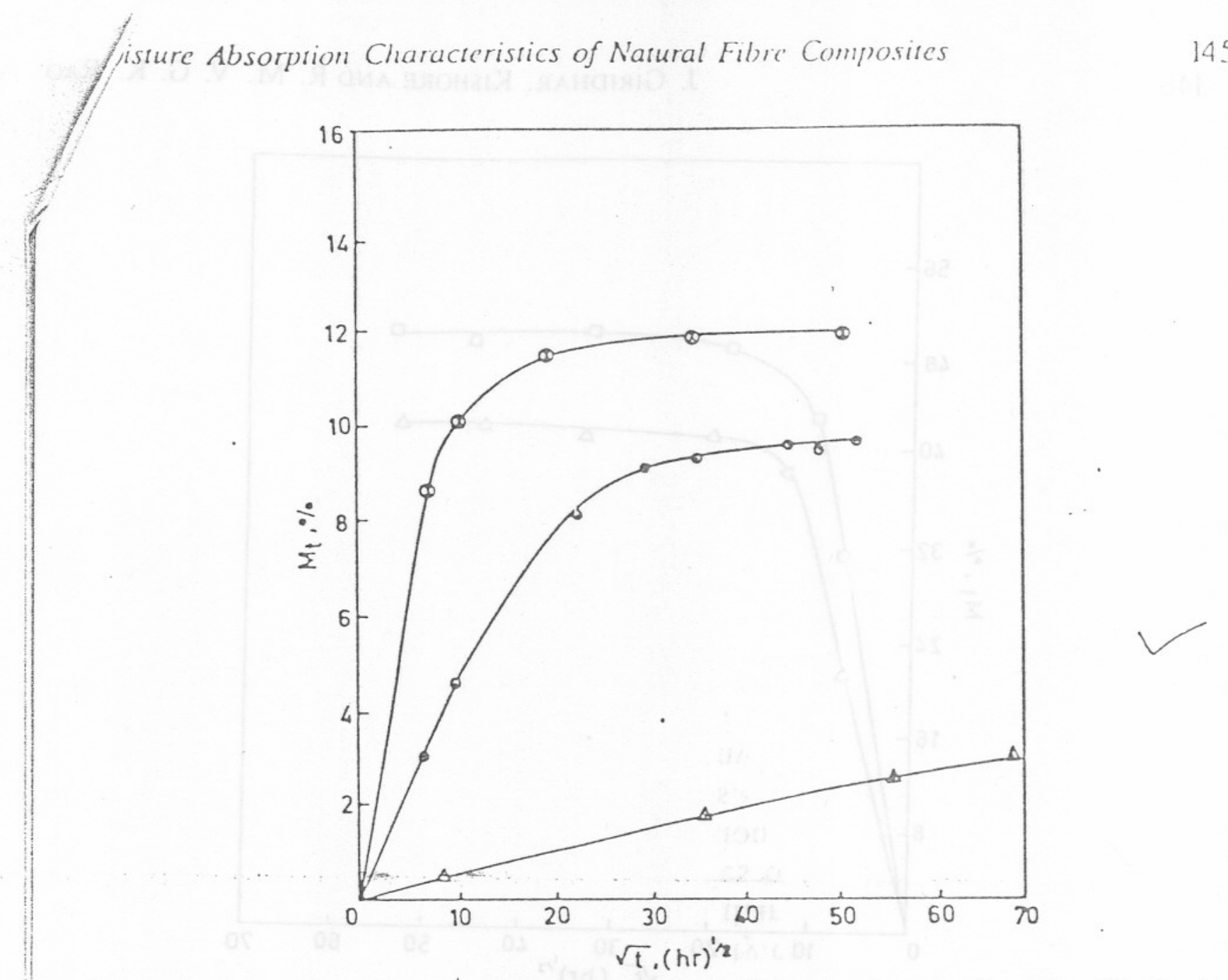

Figure 3. \% moisture absorption in jute composite at different volume fractions $\otimes-0.9 ; \odot-0.7$; $\Delta-0.0$.

volume fraction of jutefibre in the composite is increased. The absorption thend in the sisal composite with regard to the fibre volume fraction remains similar, as evident from Figure 4 ! However, it may be noted that at a volume fraction of 0.7 the absorption level of virgin sisal fibre $(70 \%$, Figure 2$)$ is reduced to only $40 \%$ upon resin impregnation, as clearly demonstrated in this figure. For the same volume fraction the absorption level of a virgin jute fibre $(140 \%)$ is brought down to as low as $9.5 \%$ (Figure 3).

This striking disparity between jute and sisal composites can be attributed on the one hand to the basic compactness of sisal fibres (and hence the low moisture absorption of virgin sisal fibres as compared to that of virgin jute fibres), and to the high cellulose content of sisal fibres (and hence the lower reduction in moisture absorption level of virgin sisal as compared to jute upon impregnation with the resin).

Thus, while the basic compactness in the physical structure accounts for the absorption level in an unimpregnated (virgin) fibre, the chemical nature (cellulose content) appears to govern largely the absorption behaviour of an impregnated fibre (the composite).

Now looking at the virgin fibres, the diffusivity of a sisal composite is a function of the diffusion coefficients of the fibre $\left(D_{f}\right)$ and the resin $\left(D_{r}\right)$. For the jute fibre, however, the composite diffusivity is controlled mostly by the resin impregnated jute fibre $\left(D_{f}^{\prime}\right)$. 


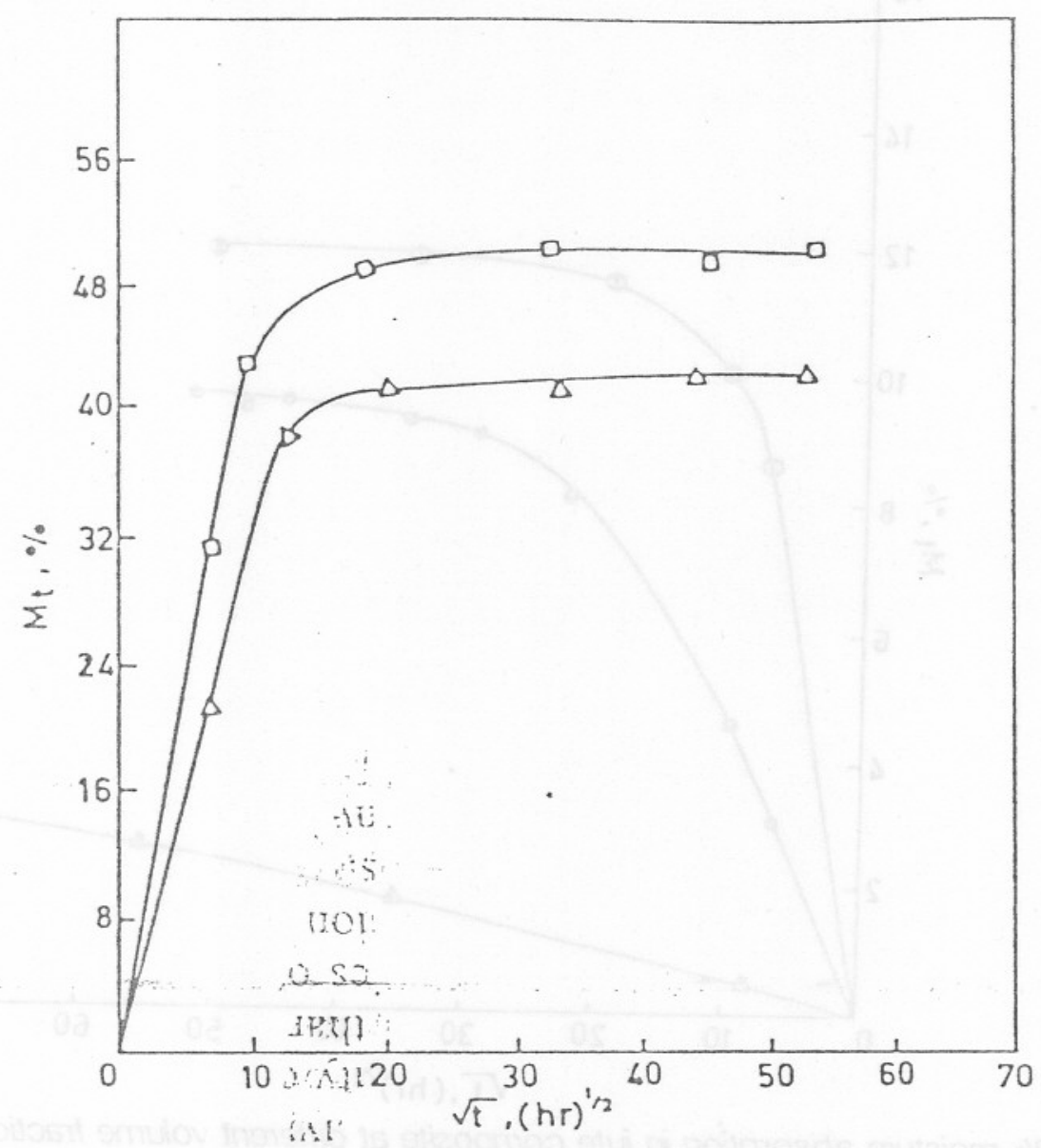

Figure 4. \% moisture absorption in sisal composite at afferent volume fractions $\square-0.8 ; \Delta-0.7$.

During experiments, it was seen that sisal fibres seldom wetted satisfactorily in the resin matrix, while the wetting of jute fibres was very good. This alsc leads to the conclusion that sisal fibres do not lend themselves as attractive rein. forcements in polymer matrices unless otherwise surface treated. It was in facl noticed that the fibres withdrew easily from the laminates when pulled from one end, with cured resin sticking all along the fibres. This then lends some credence to a possible interfacial factor also contributing to the high absorption levels ir the sisal composites.

\section{b. Fickian Correlation in Sisal-Epoxy Composites}

Figure 5 shows the superimposition of the experimental data for the sisal. composite on the analytical curve representing Equation (2). A good correlatior can be noticed for the composite at a fibre volume fraction of 0.7. Deviations: however, appear at the higher fibre fraction (0.8). Jute fibre composites, however: exhibited very good correlation at all volume fractions considered, as reported by' Rao et al.

This can be attributed largely to the non-wetting surface characteristics of the sisal fibres, as observed in these experiments. In a sisal composite, the fibre ap. peared as if encapsulated in a resin casting, while in the case of the jute com. posite, the fibres have lost their identity. 


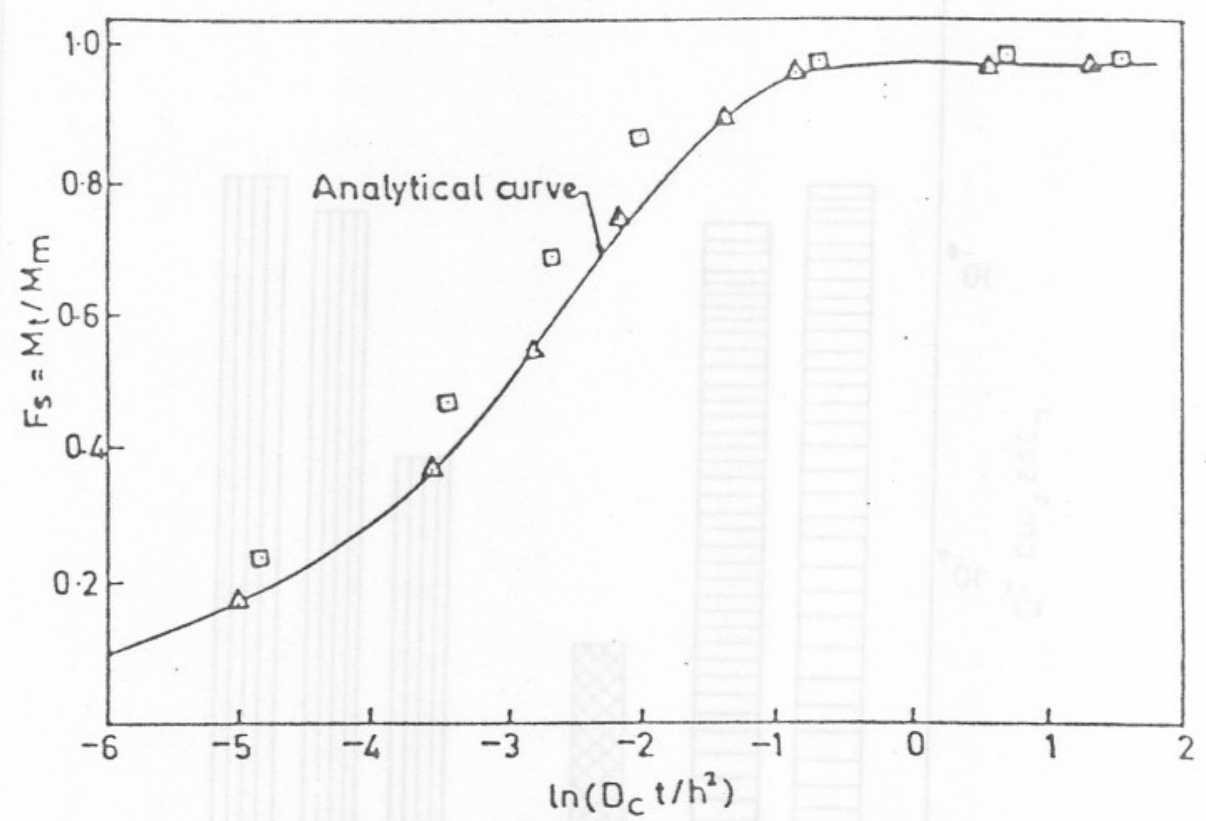

Figure 5. \% comparison of analytical (Equation 2) and measured " $F_{s}$ " values for the sisal composite. (298K, water immersion) $\odot-0.8 ; \Delta-0.7$.

\section{c. Composite Diffusivities of Natural Fibre Composites}

The diffusion coefficients of the jute and sisal composites as calculated from Equation (3) are presented in Figure 6. The overall diffusion coefficient increases with the respective fibre volume fractions for both types of composites as expected. The variation of the diffusivity index $\left(D_{c}^{\prime} / D_{r}\right)$ as given in Figure 7, however, indicates that the diffusivity of the sisal epoxy composite is more sensitive to the fibre volume fraction than that of the jute composite. This may be related to the surface characteristics of these fibres.

Table 2 shows the overall diffusion characteristics of neat-epoxy, jute-epoxy, and sisal-epoxy composite systems

At this juncture, it may be worthwhile to note that even the advanced aramid fibre composite absorbs moisture [5] to levels as high as 6\% under immersion conditions and that the absorption increases with an increase in the fibre volume fraction [6]. This, however, doesn't seem to hinder the application of these composites in advanced areas. Nevertheless, it does attract the attention of moisture absorption analysts, and it is very appropriate to establish to what extent the high levels of moisture noticed in the aramid composites affect their mechanical properties.

\section{CONCLUSIONS}

Sisal fibres are physically more compact and hence absorb less moisture than jute fibres. Their composites, however, exhibit much higher absorption levels than jute composites. This can be attributed largely to a high cellulose content in sisal fibres and to some extent to the poor fibre-resin interface noticed in these composites.

Sisal fibres appear much less promising than jute fibres, in an untreated condition, in the fabrication of composites. The cost of sisal fibres is also high as com- 


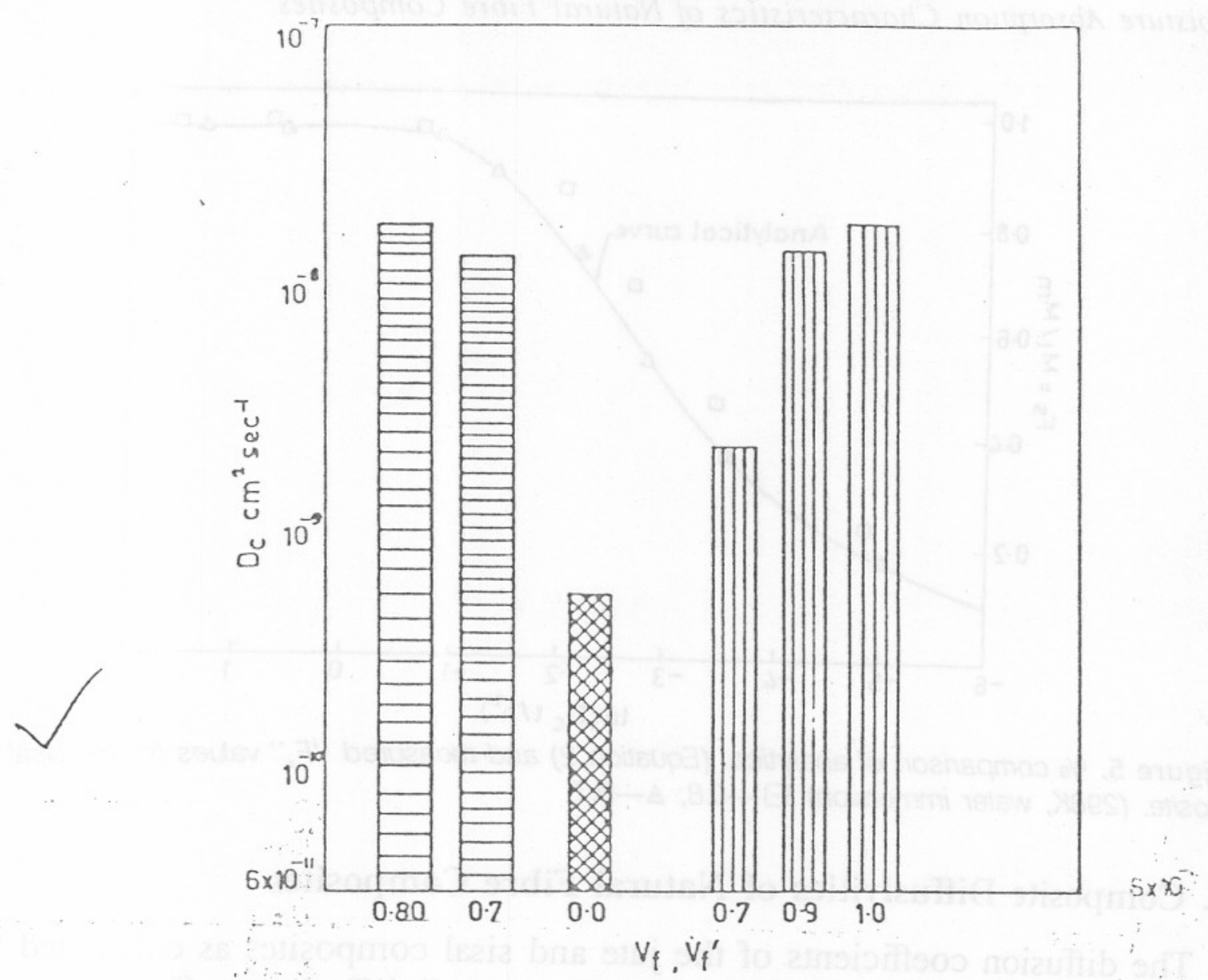

Figure 6. Comparison of diffusion coefficient of jute and sisal composites at differembfithre frac-

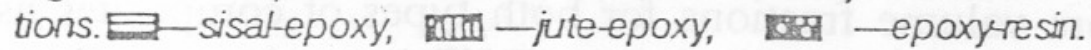
$20 x y$.

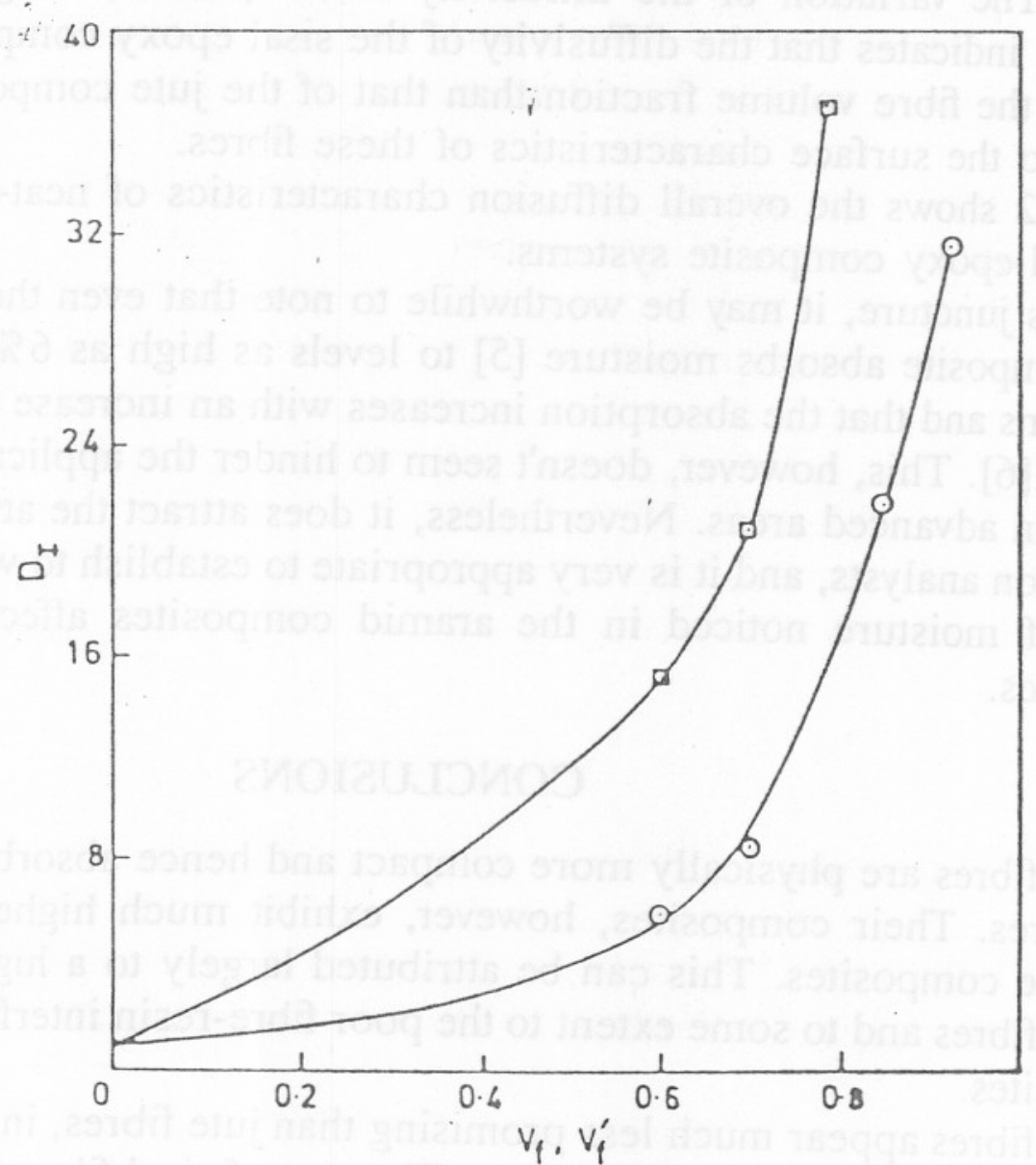

Figure 7. Variation of diffusivity index $\left(D_{l}\right)$ with fibre tractoons. - -sisal-epoxy, $\odot$-jute-epoxy. 
Table 2. Diffusion properties of overall jute-epoxy and sisal-epoxy composites.

\begin{tabular}{|c|c|c|c|c|c|}
\hline \multirow[b]{2}{*}{ Díffusion Property } & \multirow[b]{2}{*}{ Epoxy Resin } & \multicolumn{2}{|c|}{ Jute Epoxy Composite } & \multicolumn{2}{|c|}{ Sisal Epoxy Composite } \\
\hline & & $n v_{i}=0.7$ & $v_{i}=0.9$ & $v_{1}=0.7$ & $v_{1}=0.8$ \\
\hline $\begin{array}{l}\text { Equilibrium Moisture } \\
\text { Content }\left(\mathrm{M}_{\mathrm{m}}(\%)\right.\end{array}$ & 3.2 & 8.5 & 11.2 & 41.6 & 49.0 \\
\hline $\begin{array}{l}\text { Diffusion Coefficient } D_{c}^{\prime} \\
\quad \text { or } D_{c}\left(\mathrm{~cm}^{2} \mathrm{sec}^{-1}\right)\end{array}$ & $8.3 \times 10^{-10}$ & $4.5 \times 10^{-1}$ & $2.66 \times 10^{-6}$ & $1.66 \times 10^{-4}$ & $2.92 \times 10^{-2}$ \\
\hline $\begin{array}{l}\text { Applicability of Fickian } \\
\text { Diffusion Model }\end{array}$ & Applicable & \multicolumn{2}{|c|}{ Applicable } & \multicolumn{2}{|c|}{ Applicable } \\
\hline $\begin{array}{l}\text { Effect of Fibre Volume } \\
\text { Fraction }\end{array}$ & - & \multicolumn{2}{|c|}{ Increase Diffusivity } & \multicolumn{2}{|c|}{ Increase Diffusivity } \\
\hline Diffusivity Index $D_{1}$ & 1 & 5.42 & 32.1 & 20.1 & 35.1 \\
\hline
\end{tabular}

pared to jute, which places another limitation on their use in low cost composite development.

\section{NOMENCLATÚRE}

$\begin{array}{rll}D_{c}^{\prime}- & \text { Diffusion coefficient of permeable fibre composite } & \mathrm{Cm}^{2} \mathrm{Sec}^{-1} \\ F_{s}- & \text { Fractional moisture absorption } & \left(M_{\mathrm{t}} / \mathrm{M}_{\infty}\right) \\ h- & \mathrm{Cm} \\ M_{t}-\text { Specimen thickness } & \% \\ M_{\infty}-\text { Eoisture content at any time } & \% \\ t-\text { Exposure time } & \mathrm{hr}\end{array}$

\section{ACKNOWLEDGEMENTS}

The authors are grateful to the authorities of IISc and NAL for the facilities provided at the Department of Metallurgy and the Materials Science Division, respectively. They would like to thank Dr. A. K. Singh, Head, Materials Science Division for his help and interest in the work.

\section{REFERENCES}

1. Shen, Chi-Hung and Springer, George S.. "Moisture Absorption and Desorption of Composite Materials," J. Composite Materials, Vol. 10. pp. 2-20 (1976).

2. Springer, George S., "Moisture Contents of Composites under Transient Conditions," J. Composite Materials, Vol. 11, pp. 107-122 (1977).

3. Romanenkov, I. G. and Machavariani, Z. P., "Water Absorption of GRPS," Soviet Plastics, pp. 49-51 (June 1966).

4. Rao, R. M. V. G. K., Chanda, Manas and Balasubramanian, N., "A Fickian Diffusion Model for Permeable Fibre Polymer Composites." J. Reinforced Plastics and Composites, Vol. 2 (October 1983). 
5. Lo, S. Y. and Hahn, H. T., -Swelling of Kevlar-49/Epoxy and S2 Glass/Epoxy Composites," Progress in Science and Engineering of Composites (1982).

6. Gopalan, R., Rao, R. M. V. G. K., Murthy, M. V. V. and Dattaguru, B., "Diffusion Studies on High Performance Hybrid Composites," Communicated to the J. Reinforced Plastics and Composites, for publication. 